\title{
Sistema Milk-Run para o abastecimento interno de células de manufatura: um estudo de caso no setor de autopeças
}

\section{Milk-Run system to supply manufacturing cells: a case study in auto parts industry}

\author{
Joice ArIane Marin' \\ André LuÍS HeLLeNo" \\ AleXANDRE TADEU SIMON ${ }^{\prime \prime \prime}$
}

\begin{abstract}
Resumo O Sistema Milk-run é uma ferramenta da logística que pode ser usada tanto para o abastecimento externo da matéria-prima nas fábricas, como para o abastecimento interno nas células de manufatura. Este artigo apresenta as vantagens da utilização do sistema Milk-run no ambiente interno, ou seja, dentro das plantas fabris, para o abastecimento das células de manufatura. Além do levantamento bibliográfico acerca dos benefícios e os requisitos necessários para a implementação do sistema, foi realizado um estudo de caso em uma empresa do setor de autopeças; no qual a célula de manufatura foi otimizada por meio de três cenários. Concluiu-se que os cenários otimizados por meio de uso do Milk-run mostraram muitos benefícios como redução de estoque em processo e aumento de produtividade.
\end{abstract}

Palavras chave: Milk-run. Logística. Células de manufatura.

Aвstract Milk-run system is a logistics appliance that can be used to supply either external raw materials of plants or internal supply of manufacturing cells. The current study presents the advantages and benefits of in-plant Milk-run logistics applications, including the needs for implementation and methods to determine the essential parameters. Also is presented a case in autoparts industry, suggesting tree possible scenarios. The results proved that scenarios with milk-run shows improvements like work in process reductions e increase of productivity.

KeY-words: MilK-RUn. Logistics. MANufACtURING CelLS.

\footnotetext{
${ }^{\mathrm{I}}$ Universidade Metodista de Piracicaba (UNIMEP), Santa Bárbara d'Oeste/SP - Brasil.

"Universidade Metodista de Piracicaba (UNIMEP), Santa Bárbara d'Oeste/SP - Brasil.

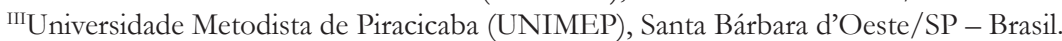




\section{INTRODUÇÃO}

Empresas do setor de autopeças vêm buscando técnicas e ferramentas que as auxiliem na racionalização de recursos, principalmente aqueles que não agregam valor ao produto, na visão do consumidor. Alguns desses recursos são: manuseio de materiais, recursos humanos, estrutura física e transporte. Segundo Womack, Jones e Roos (2008), a definição de desperdício é: "Qualquer quantidade maior do que o mínimo necessário de equipamento, materiais, componentes e tempo de trabalho essencial à produção". Para reduzir os desperdícios no transporte, Corrêa e Gianesi (1993) destacaram que é necessário elaborar arranjos físicos que possibilitem a menor movimentação dos materiais, pois a movimentação não agrega valor ao produto.

Um dos maiores pesquisadores da logística, Ballou (2006), apresenta a seguinte definição: "Logística é o processo de planejamento, implantação e controle do fluxo eficiente e eficaz de mercadorias, serviços e das informações relativas desde o ponto de origem até o ponto de consumo com o propósito de atender às exigências dos clientes".

Toda vez que se pretende "racionalizar ou enxugar" recursos, é necessário cuidado e cautela, para que não haja perda de qualidade e cumprimento de prazos, entre muitas outras exigências do consumidor. Pois, dessa forma, ao invés de ganhar, se perderia competitividade, mesmo reduzindo custos. Em função dessas necessidades, o sistema Milk-run ganhou força e adesão por muitas empresas, pois é uma ferramenta que permite racionalizar recursos com grande comprometimento de prazos e entregas (ZHANG, ZOU e HU, 2016).

Kilic, Durmusoglu e Baskak (2012) fizeram uma analogia, afirmando que se o "pensamento enxuto" da manufatura enxuta é aplicado em logística, no sentido de reduzir desperdício, a logística pode ser considerada enxuta. Eles destacam três grupos principais dentro da logística: abastecimento (do fornecedor para a fábrica), interno (logística dentro da fábrica) e externo ou distribuição (da fábrica para o consumidor). Dentro desses grupos, pode-se assegurar que o método Milk-run foi desenvolvimento inicialmente para o abastecimento do fornecedor para a fábrica.

A contratação de serviços de transportes deve ter como premissa a qualidade do serviço contratado, com base em relacionamentos de parceria e confiança, a fim de obter melhores desempenhos e o menor impacto em relação ao custo de frete no produto (RODRIGUES et al., 2016).

Quando um bom sistema de manuseio de materiais é adotado, o custo pode reduzir entre $10 \%$ e $30 \%$. O manuseio de materiais normalmente utiliza até $25 \%$ dos trabalhadores, $55 \%$ da área da fábrica e pode ser responsável por até $87 \%$ do tempo de produção. O sistema Milk-run determina as rotas, o horário, o tipo e o número de peças que veículos diferentes devem transportar (SADJADI, JAFARI e AMINI, 2009).

Delmo e Botter (2002) afirmaram que o sistema de coleta programada de peças, Milk--run, é uma realidade nas montadoras instaladas no Brasil. Uma grande parcela delas já implantou ou está em fase de implantação. Cardoso e Jó (2008) constataram em seu trabalho que a prática do sistema Milk-Run é utilizada principalmente pelas montadoras de automóveis, para coletar peças em seus fornecedores externos. Estudando três montadoras, puderam observar que to- 
das visam a redução do custo de transporte e o abastecimento da linha de produção de forma estável e confiável.

Mazzali e Milan (2006) afirmaram que muitas empresas estão aplicando o sistema de coletas programadas (Milk Run), com o objetivo de atender no momento exato e com o menor custo. Esse sistema envolve fornecedores, operadores logísticos (em alguns casos) e montadoras.

Tao, Zhao e Zhu (2016) desenvolveram um modelo para a definição dos períodos de entrega e conseguiram comprovar por meio de estudo de caso a redução dos custos de entrega com a implementação do Milk-run.

Outro modelo foi desenvolvido por Zhang, Zou e Hu (2016) para a definição das rotinas do Milk-run, considerando principalmente a capacidade de carga dos veículos e a frequência do transporte. Os autores aplicaram o modelo em um estudo de caso e conseguiram reduzir o lead time dos produtos.

As vantagens obtidas com a implementação do Milk-run são muito amplas e abrangem desde custo, produtividade, fidelização até sustentabilidade.

Um dos objetivos deste artigo é apresentar as vantagens da utilização da ferramenta logística Milk-run, tanto para o abastecimento entre fábricas e fornecedores como internamente, entre almoxarifados e células de manufatura (item 2). Também são exibidos métodos para analisar e determinar a implementação do mesmo. Para isso, foi realizada uma pesquisa bibliográfica em artigos e livros relacionados ao assunto.

O segundo objetivo é analisar a implementação do Milk-run para o abastecimento de células, propor diferentes cenários e levantar quantitativamente os possíveis ganhos com a sua implementação (item 3). Para alcançar esse objetivo, foi realizado um estudo de caso (item 4) em duas células de manufatura numa empresa do setor de autopeças. Análise e discussão dos resultados obtidos no estudo de caso é realizada no item 5 e então, é apresentada a conclusão da pesquisa.

\section{Características e vantagens do Milk-Run}

O Milk-Run é uma ferramenta logística de abastecimento (inbound). Segundo Pires (2004), essa ferramenta leva esse nome por ter sido inspirada nos tradicionais sistemas de abastecimento das usinas pasteurizadoras de leite, que possuíam um veículo dedicado a realizar a coleta do leite em pequenos produtores utilizando uma rota com horário determinado.

Embora o nome tenha sido inspirado numa prática simples e antiga, muito foi acrescentado e desenvolvido, tornando essa ferramenta uma ótima solução para o abastecimento das fábricas (LIN et al., 2015). Trabalhos recentes apontam as vantagens da implementação dessa ferramenta (ZHANG, ZOU e HU, 2016), bem como, métodos para a determinação dos parâmetros necessários para a implementação no ambiente interno.

A figura 1 a seguir mostra a alteração do fluxo dos veículos de transporte ao adotar o sistema Milk-run na cadeia de suprimentos. Para compreender melhor, podemos considerar que o destino de consumo seria uma montadora de automóveis, os fornecedores A, B, C e D podem ser empresas que fornecem peças diversas para a montadora. 


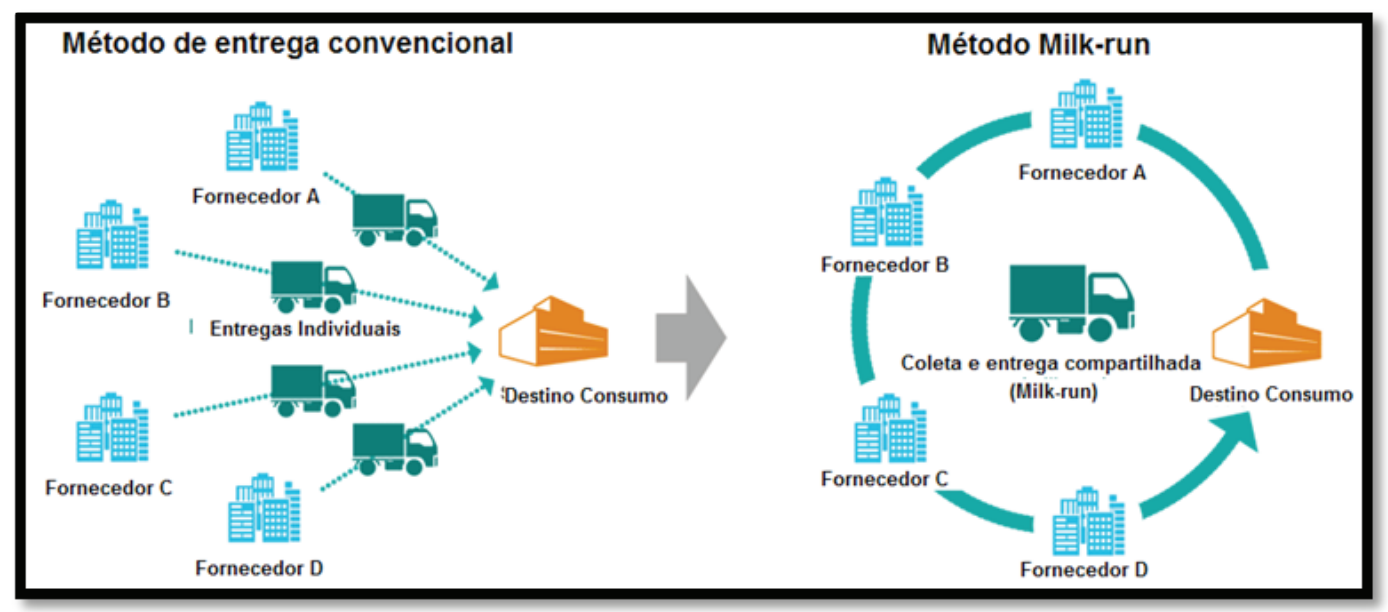

No sistema de entrega convencional (à esquerda), cada empresa é responsável por entregar seu produto na montadora. Gerando um grande número de caminhões nas docas (almoxarifados), grande número de "paletes", falta de aproveitamento do espaço total nos carros e na hipótese de algum fornecedor descumprir a entrega a montadora pode demorar a perceber a falha ou o atraso. No método Milk-run (à direita), a montadora é responsável pela coleta das peças, determinando uma rota com horário específico, eliminando desperdícios e trazendo muitas vantagens.

No método convencional, a montadora compra no sistema CIF (Cost Insurance and Frei$g h t)$, isto é, o frete é de responsabilidade e custo dos fornecedores (A-D). Ao implementar o Milk-run, a montadora passa a comprar no sistema FOB (Free on Board), ou seja, ela passa a ser responsável pela coleta e custo do transporte. No primeiro momento, pode-se imaginar que o custo irá aumentar, pois ela incorpora a despesa de transporte, mas é necessário analisar a cadeia de suprimentos como um todo, desagregar o custo do produto ao do transporte e assim visualizar o ganho na cadeia e não apenas pontualmente.

Para Rohm et al. (2010), o foco principal do Milk-run é ter um sistema de abastecimento com roteiros e horários predefinidos para as coletas de materiais junto aos fornecedores com um único veículo. Um dos objetivos é reduzir os custos logísticos de abastecimento via economias de escala e racionalização das rotas, bem como, aumentar a confiabilidade do processo como um todo. Em princípio, o processo pode ser realizado pela empresa cliente mas, em geral, é feito por operadores logísticos especializados, os quais proporcionam maiores ganhos em escala.

Para Delmo e Botter (2002), muitas empresas possuem um operador logístico/transportador para realizar a operação de coleta programada, porém existem algumas empresas que preferem executar a coleta de peças com sua própria frota para conhecer todos os custos inerentes com a operação antes de compartilhar essa tarefa com um operador logístico. Independentemente da forma que estão adotando para realizar a operação (com ou sem operador logístico), o certo é que todas elas estão percorrendo o mesmo caminho, adotando o sistema 
de coleta programada de peças, que também representa um passo enorme para o sistema de trabalho Just-in-time (JIT).

O Milk-run é reconhecido por muitos autores como um fator que auxilia e melhora significantemente a política JIT na cadeia de suprimentos (TAO, ZHAO e HU, 2016), isso ocorre como uma função das vantagens alcançadas com a implementação desse método. Quando a montadora adota esse método automaticamente, os fornecedores recebem uma "pressão" ainda maior no cumprimento de prazos e lotes, pois, se não o realizarem, perdem a "coleta", e por conseguinte, a credibilidade, passando a ser vistos como um "empecilho" no bom funcionamento do sistema.

Os autores Sadjadi, Jafari e Amini (2009), Delmo e Botter (2002) e Moura (2002) apontaram em seus trabalhos as principais vantagens do Milk-run, como redução do custo devido ao uso eficaz do espaço dos veículos de transporte (volume e/ou peso) e maior controle da carga, portanto, haverá redução da manutenção de veículos e redução dos tempos ociosos durante o carregamento e descarregamento.

Eles apontaram também que há um melhor nivelamento do fluxo diário de recebimento de materiais; aumentando a frequência de abastecimento, alimentando a montadora apenas com as peças necessárias, nas quantidades necessárias, na hora solicitada e dentro das embalagens padronizadas; apresentando ganho de precisão e de melhorias no uso do sistema Just-in-time; maior sincronia entre fornecedores e clientes. Com isso, pode ocorrer redução do nível dos estoques inclusive nos fornecedores; potencializando o giro de estoque e o retorno de capital.

Essas racionalizações proporcionam uma melhora significativa nos parâmetros de sustentabilidade da cadeia. Podemos destacar algumas, como menores emissões de gás pelos veículos, racionalizações de estoques e espaços. Keller e Kuylenstierna (2016) realizaram um estudo de caso para a implementação do Milk-run em uma empresa na Alemanha, incluindo entrevistas com pelo menos 45 gestores em toda a cadeia de suprimentos da empresa, o que apontou a preocupação da maioria no aumento da responsabilidade e redução do impacto ambiental na cadeia de suprimentos.

Assim, o Milk-run tem sido adotado por muitas empresas e também tem sido foco de estudos e pesquisas, pois possui características que contribuem em nivelar e estabelecer uma boa disciplina em operações logísticas, possibilitando um aumento do desempenho na cadeia de suprimentos como um todo e redução dos impactos ambientais.

Algumas boas práticas se fazem necessárias para que o método Milk-run possa funcionar adequadamente, como treinamento de mão de obra, padronização de embalagem e confiabilidade.

Existem situações que não são adequadas à implementação do método Milk-run, principalmente em função do percurso e volume dos itens transportados. Com relação ao percurso, uma das restrições é quando a distância entre o fornecedor e a montadora é muito grande, ou quando os fornecedores estão localizados em pontos metropolitanos de extremo tráfego, com grandes variações de fluxo, que impossibilitam o cumprimento de horários e que podem comprometer todo o processo. 
Outra restrição é quando o volume do produto a ser transportado é grande, um exemplo dado por Nemoto, Katsuhiko e Masataka (2010) são bancos de carros, cujo consumo diário da montadora pode ocupar todo o volume de um ou mais veículos, então, em casos como esses não há como realizar o compartilhamento dos veículos.

\section{Milk-Run para o abastecimento interno}

Após implementar e constatar as vantagens da utilização do Milk-run no abastecimento das fábricas, notou-se que o mesmo poderia ser adaptado e implementado dentro das fábricas, passando a ser utilizado também no abastecimento interno de células de manufatura. O método segue os mesmos conceitos com rotas, horários e lotes predeterminados. Os ganhos e as diretrizes são muito parecidos com algumas adaptações.

É comum observar em fábricas excesso de empilhadeiras (ou outros veículos), dando inúmeras viagens para abastecer células de produção aleatoriamente, conforme for sendo solicitado, isso gera um grande fluxo e necessidade de muitos veículos de transporte. Com a implementação do sistema Milk-run, esse fluxo pode ser reduzido e mais organizado.

Os veículos iniciam nos estoques e visitam as células de manufatura ou estações e depois retornam ao ponto de origem. Normalmente, são utilizados "trens" Milk-run para que se possa levar material suficiente para a rota determinada. Esses trens são configurados por uma empilhadeira e módulos de transporte a fim de aumentar sua capacidade.

Em algumas situações, não é possível implementar o sistema Milk-run para a planta completamente, em função das restrições que são similares ao método tradicional, como peças muito pesadas e/ou com grande volume. Nesses casos, podem ser implementados sistemas híbridos com abastecimento tradicional e Milk-run.

Sem a utilização de um método programado de abastecimento, podem ocorrer situações em que, mesmo dispondo de um grande número de veículos, estejam todos ocupados e as células parem por falta de abastecimento, e com isso ocorra o aumento dos estoques nas estações de trabalho para compensar essas situações. Em outros momentos, porém, pode haver veículos ociosos. Com a implantação do método, é possível planejar e otimizar o período de uso dos veículos e o abastecimento das células, evitando que esses picos ocorram, sem a necessidade de aumentar os estoques, com isso, padronizando o manuseio do material e eliminando desperdícios.

Existe um contraponto entre os materiais em processo (WIP) e o custo do transporte nos veículos e o custo fixo dos veículos. Se o veículo faz viagens muito frequentes, o WIP diminui, mas, por sua vez, o custo do transporte aumenta, e ao contrário, se o veículo faz poucas viagens, o custo do transporte diminui, mas o WIP aumenta. Por isso, é essencial realizar um bom dimensionamento e planejamento do sistema.

Kilic, Durmusoglu e Baskak (2012) ressaltaram os principais parâmetros que precisam ser definidos para a implementação interna do método Milk-run, que são: determinar o período das viagens, determinar o lote de peças para cada estação e determinar a rota do veículo. Os autores ressaltam que é importante analisar cada caso, e alguns fatores precisam ser considera- 
dos, como a relação entre células, o inventário que dependerá mais do ciclo do veículo do que de uma quantidade fixa, atentar para as restrições físicas das áreas de estoque e manuseio de múltiplas categorias de produtos.

O modelo matemático é capaz de realizar o dimensionamento do sistema de forma eficaz, assim como a simulação. Muitos dos modelos matemáticos encontrados na literatura são voltados para o sistema Milk-run externo, porém já existem trabalhos voltados para o sistema interno. Recentemente, Kilic, Durmusoglu e Baskak (2012) desenvolveram um método matemático para a classificação e o modelamento de sistemas Milk-run internos, com uma ampla abordagem dos quesitos a serem levantados, analisados e dimensionados.

A simulação é uma ferramenta inovadora que permite visualizar a manufatura, os estoques e os fluxos em um ambiente virtual; com isso, é possível realizar análises, previsões, testes, verificar o comportamento do sistema em função das alterações e assim concluir o melhor modelo de trabalho antes de investir recursos financeiros e operacionais que poderiam não trazer o retorno esperado. Azedeh, Shirkouhi e Rezaie (2010) afirmaram que muitos problemas complexos, do mundo real, podem ser solucionados mais facilmente com o auxílio da simulação.

A Simulação Virtual é um termo muito empregado atualmente, e com isso muitas definições são encontradas. Uma delas explica que a simulação virtual é a integração de modelos computacionais que representam a estrutura completa e precisa dos sistemas de manufatura e a simulação de seus comportamentos lógicos e físicos para auxiliar o projeto e a produção de produtos (IWATA et al., 2005).

Os autores Merdan et al. (2011), Rathinasamy e Raju (2010), Pádua (2012) e Oliveira (2008) destacam que uma das grandes vantagens do uso da simulação é o ganho e tempo, pois com a simulação pode-se testar e analisar uma ampla gama de opções de configurações do sistema, criando e analisando diversos cenários, chegando a conclusões e adquirindo um conhecimento de forma muito mais rápida do que realizando os testes no mundo-real.

Kimura (2003) e Netto et al. (1998) afirmaram em seus trabalhos que a Simulação Virtual permite visualizar alternativas de fluxo de produção, avaliando diversos cenários, com variáveis nos indicadores de desempenho, otimizando o processo de fabricação de cada produto, com foco em custos e rapidez nas tomadas de decisão. Anvari et al. (2010) completam, afirmando que, na manufatura especialmente, a simulação pode ajudar gerentes a identificar a melhor solução.

Assim, a simulação pode ser uma ferramenta de grande eficiência na implementação do sistema Milk-run, pois permitiria simular as rotas entre as células, os horários, bem como, a quantidade dos estoques nas estações e o consumo das máquinas, tudo isso em diversas configurações até se obter um modelo que seja adequado e viável para a implementação.

\section{Estudo de CASO}

O estudo de caso realizado envolve a criação de três cenários para a análise dos benefícios obtidos com a implementação do Milk-run no abastecimento de duas células de manufatura (estado 0, ver figura 2), bem como, um aumento de produtividade, tanto com a implementação do sistema como com a contratação de mais um operador. 
As células estão posicionadas uma em frente à outra (espelho). Cada peça passa por somente uma das células. A usinagem de cada peça é composta por duas operações, as operações A.1, B.1, A.2 e B.2 para as células 1 e 2 respectivamente. A figura 2 ilustra os estados 0 e 1 das células de manufatura e a figura 3 ilustra os estados 2 e 3 .

Figura 2: Cenário atual (Estado 0) e sugestão de implementação milk-run (Estado 1).
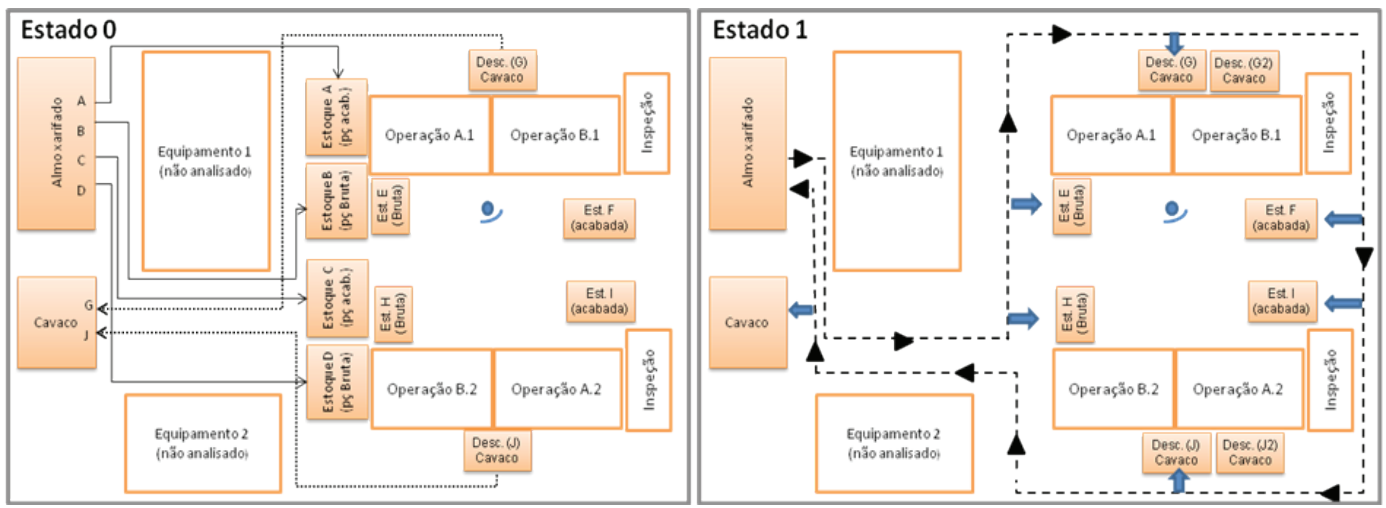

Figura 3: Estado 2 e Estado 3 analisados.
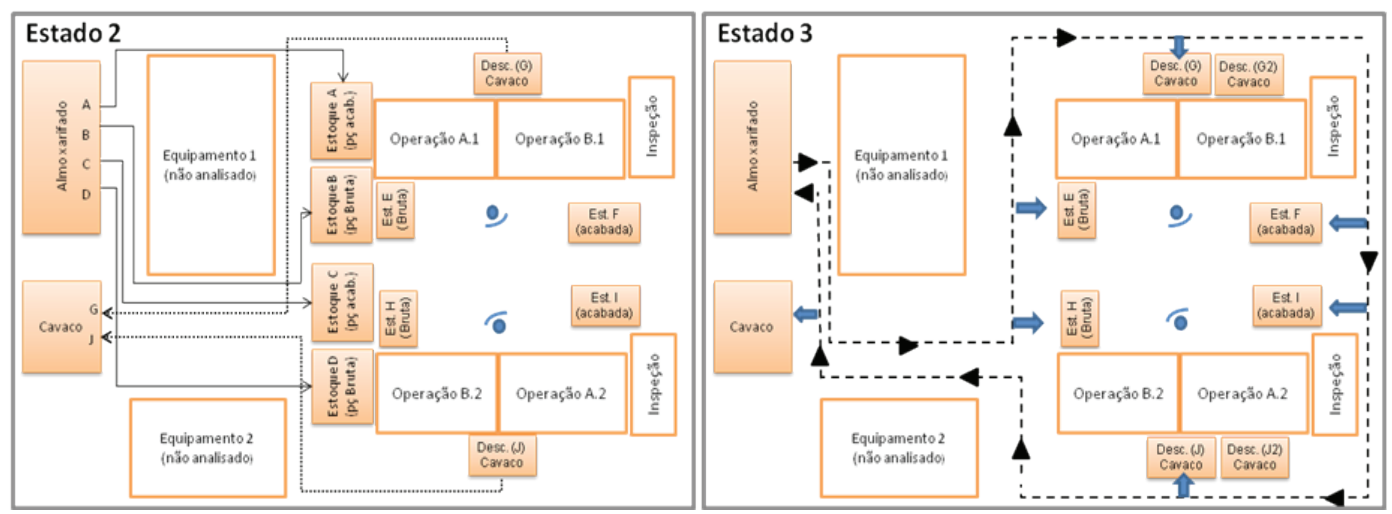

Observando as figuras 2 e 3, tem-se que:

Estado 0 - Cenário Atual (duas células, um operador, abastecimento convencional). No cenário atual, as duas células são operadas por um operador e os estoques são abastecidos de forma convencional. Uma empilhadeira realiza quatro viagens ao dia, duas para abastecer os estoques de peças brutas e duas para retirar os estoques de peças acabadas. Essas viagens são feitas no início e ao final do dia.

Estado 1 - (duas células, um operador, abastecimento Milk-run): Esse cenário foi proposto incluindo o método de Milk-run para o abastecimento das células. A principal diferença é que, ao invés de realizar quatro viagens aleatórias para o abastecimento da célula, as viagens são feitas a cada 2 horas. Os investimentos consistem na implementação do “trem” Milk-run. 
Estado 2 - (duas células, dois operadores, abastecimento convencional): Nesse cenário, foi analisado o aumento de produção, considerando a contratação de um operador e mantendo o sistema de abastecimento convencional atual.

Estado 3 - (duas células, dois operadores, abastecimento Milk-run): O terceiro cenário proposto considera dois operadores e o sistema Milk-run com relação ao estado 0.

\subsection{Variáveis do processo}

Os dados de tempo e variáveis do processo foram obtidos por meio do acompanhamento e observação das células.

No estado 0, a cada cinco peças produzidas, uma deve ser inspecionada na bancada de inspeção. O tempo desse processo é de 60 segundos, incluindo o deslocamento do operador. Cada célula possui um estoque com capacidade para um dia de produção e um estoque menor que fica mais próximo ao operador, tanto para peças brutas (estoques B, D, H E), como para peças acabadas (A, C, F, I). Todas as peças vêm do almoxarifado e devem retornar para o mesmo. As células também possuem um recipiente para o acúmulo de cavaco (G e J), com capacidade para 2 horas, após esse período, precisa ser descartado, esse procedimento dura 5 minutos. Os equipamentos 1 e 2 não foram incluídos na análise.

Há um intervalo de 10 segundos entre a operação A e B. Entre a operação B, e reiniciar A, há um intervalo de 50 segundos. O Tempo de usinagem de uma peça (operação A + B) é de 91 segundos. A tabela 1 apresenta as variáveis do processo.

Tabela 1: Produção e variáveis do processo para cada estado proposto.

\begin{tabular}{|c|c|c|c|c|c|c|}
\cline { 2 - 7 } \multicolumn{1}{c|}{} & $\begin{array}{c}\text { Parada } \\
\text { Cavaco (s) }\end{array}$ & $\begin{array}{c}\text { Parada } \\
\text { Ferramenta (s) }\end{array}$ & $\begin{array}{c}\text { Parada } \\
\text { operador (s) }\end{array}$ & $\begin{array}{c}\text { Tempo médio } \\
\text { Produção (s) }\end{array}$ & $\begin{array}{c}\text { Intervalo } \\
\text { Ciclo (s) }\end{array}$ & $\begin{array}{c}\text { Produção } \\
\text { (peças) }\end{array}$ \\
\hline Estado 0 & 2400 & 1920 & 1800 & 103 & 10 & 419 \\
\hline Estado 1 & & 1920 & 1800 & 101 & 10 & 533 \\
\hline Estado 2 & 2400 & 1920 & $3600^{*}$ & 103 & 50 & 517 \\
\hline Estado 3 & & 1920 & $3600^{*}$ & 93 & 50 & 595 \\
\hline
\end{tabular}

*Foi considerado que os intervalos dos operadores serão intercalados, portanto as células não param, mas passam a ser operadas ambas por um operador, no ritmo do estado correspondente.

- Parada Cavaco: Indica em segundos o tempo que o processo fica parado enquanto o operador leva o reservatório para ser esvaziado.

- Parada Ferramenta: A ferramenta é trocada a cada 30 minutos, e demora 60 segundos.

- Parada operador: Engloba a pausa diária para café e por outros motivos.

- Tempo médio de produção: Esse tempo é maior que o tempo de usinagem em função das paradas diversas.

- Intervalo Ciclo: Nos estados 0 e 1, indica o tempo entre o final do ciclo B2 e o início do ciclo A1. Nos estados 2 e 3, indica o tempo entre final de B e A da mesma célula. A análise foi realizada considerando que todas as atividades extras feitas pelo opera- 
dor, como inspeção e transferência de estoque, devem ser realizadas exatamente no início desse intervalo, aproveitando assim esse período.

- $\quad$ Produção: Indica a quantidade de peças produzidas no período de 8 horas.

$\mathrm{Na}$ tabela 2, o percentual do ganho de produtividade foi calculado por meio de comparação da produção (peças) dos Estados 1, 2 e 3 com relação à produção do Estado 0.

Tabela 2: Comparação de cenários e ganho produtivo para os estados analisados.

\begin{tabular}{|c|c|c|c|c|c|}
\cline { 2 - 6 } \multicolumn{1}{c|}{} & Operadores & Abas tecimento & Investimento & $\begin{array}{c}\text { Produção } \\
\text { (peças) }\end{array}$ & $\begin{array}{c}\text { Ganho de } \\
\text { Produtividade }\end{array}$ \\
\hline Estado 0 & 1 operador & convencional & -------- & 455 & \\
\hline Estado 1 & 1 operador & Milk-run & $\begin{array}{c}-2 \text { reservatórios para cavaco } \\
\text { - engate para reservatórios }\end{array}$ & 533 & $17 \%$ \\
\hline Estado 2 & 2 operadores & convencional & - contratação 1 operador & 517 & $14 \%$ \\
\hline Estado 3 & 2 operadores & Milk-run & $\begin{array}{c}\text { - 2 reservatórios para cavaco } \\
\text { - engate para reservatórios } \\
\text { - contratação 1 operador }\end{array}$ & 595 & $31 \%$ \\
\hline
\end{tabular}

\section{ANÁlise e discussÃo dos RESUltados}

Nos estados 1 e 3, temos uma série de vantagens relacionadas à implantação do Milk-run para o abastecimento das células. Além de pouco investimento para a sua implementação, ele apresenta vantagens relacionadas à logística e também ganho de produtividade.

Com relação à logística do processo, um dos benefícios obtidos foi a organização do fluxo de materiais. Comparando as imagens, pode-se avaliar melhor que, ao invés de quatro viagens para o estoque $(A, B, C, D)$ e oito viagens com reservatório de cavaco $(G, J)$, todos em sentido de ida e volta, tem-se apenas um ciclo realizado quatro vezes ao dia. Esse ganho torna-se ainda mais relevante se considerar que há uma redução na demanda da empilhadeira, principalmente no início do turno, horário em que há um pico de demanda desse recurso.

Outro benefício é a redução significante de estoque de peças brutas e acabadas na célula, e com isso também a redução de espaço ocupado por esses estoques. Essas vantagens já justificariam a implementação no Milk-run, mas nesse caso estudado, obtém-se ainda o ganho de produtividade, que chega a ser de $17 \%$ para o Estado 1, conforme tabela 2.

Nem sempre é possível obter ganho de produtividade com a implementação do sistema Milk-run, principalmente significativa dessa forma, usualmente o ganho está relacionado a questões logísticas. Nesse caso em especial, há alguns fatores que proporcionaram esse ganho. Um deles é o descarte de cavaco que deixa de ser responsabilidade do operador; outro fator é que o operador não trabalha mais com grandes estoques e, portanto, não necessita ficar realizando a transferência de peças das caixas menores para maiores, e assim por diante. Com isso, é possível aproveitar o intervalo entre os ciclos para realizar inspeção na peça reduzindo significantemente o tempo que a máquina fica ociosa. 
A implementação do sistema mostra-se tão eficiente que supera a contratação de mais um operador (estado 2) que apresenta um ganho de produtividade de 14\%.

O Estado 3 apresenta o maior ganho produtivo com relação ao cenário atual, aumentando em 31\%, pois considera a contratação de um operador e a implementação do sistema Milk-run.

Assim o estudo de caso comprova os benefícios e as vantagens que podem ser alcançados com a implementação do sistema Milk-run, no ambiente interno das fábricas, para o abastecimento de células de manufatura.

O estudo não estendeu-se até o momento em indicar qual seria o estado ideal para a implementação no caso estudado. O estado 3 pode parecer o mais indicado, pois apresenta o maior ganho de produtividade, porém inclui o aumento de um operador. Para realizar essa indicação, é necessário avaliar o lucro obtido com o aumento da produção, os custos da contratação e a demanda do produto. É possível que o Estado 1, que apresenta um investimento baixíssimo e ganho de 17\%, atenda às necessidades. O que se pode afirmar é que o estado ideal seria 1 ou 3, porém, para eleger um dos dois, muitos fatores precisam ser avaliados.

\section{CONSIDERAÇÕES FINAIS}

Com base na literatura, é possível afirmar que o sistema logístico de abastecimento Milk-run tem sido amplamente utilizado pela indústria, inclusive no Brasil, principalmente no setor de autopeças; e que a tendência de migração desse sistema para o ambiente interno, no abastecimento de células, é forte e já começou a ser realizada.

Com o estudo de caso realizado para este artigo, fica constatado que o ganho pode transcender as barreiras logísticas, com as inúmeras vantagens já relacionadas; e apresentar ganhos também em produtividade e muitos outros aspectos, dependendo das características de cada caso. A simulação é uma ferramenta que pode auxiliar no planejamento e dimensionamento de todos esses dados antes da implementação no sistema real, indicando qual o cenário ideal para a aplicação em cada caso.

\section{ReFERÊNCIAS}

ANVARI, M.; MEHRABAD, M. S.; AZADEH, A.; SABERI, M. Performance assessment of decision-making unitsusing an adaptive neural network algorithm: one period case. International Journal Of Advanced Manufacturing Technology, v. 46(9-12), p. 1.059-1.069, 2010. AZADEH, A.; SHIRKOUHI, S. N.; REZAIE, K. A robust decision-making methodology forevaluation and selection of simulation software package. International Journal Of Advanced Manufacturing Technology, v. 47(1-4), p. 381-393, 2010.

BALLOU, R. H. Gerenciamento da cadeia de suprimentos: logística empresarial. Bookman, 2006.

CARDOSO, P. A., \& JÓ, M. Y. A prática do Milk Run no Fornecimento a indústria Automobilística do Brasil. IV Congresso Nacional de excelência em Gestão, 2008. 
CORRÊA, H. L.; GIANESI, I. G. N. Just in Time, MRPII e OPT: um enfoque estratégico, 2. ed. São Paulo: Atlas, 1993.

DELMO, A. M.; BOT'TER, R. C. Caracterização do sistema de coleta programada de pecas, Milk Run. RAE Eletronica, jan., v. 1(1), 2002.

IWATA, K. et al. "A modelling and simulation architecture form virtual manufacturing systems", Annals of the CIRP, p. 399-402, v. 44. January, 2005.

KELLER, M.; KUYLENSTIERNA, I. Future Customer Demand on the Supply Chain and Contribution of the Milk Run Concept at Iggesund Paperboard AB. Umeå University. Suécia, 2016.

KILIC, H. S.; DURMUSOGLU, M. B.; BASKAK, M. Classification and modeling for in-plant milk-run distribution systems. International Journal Of Advanced Manufacturing Technology, v. 62(9-12), p. 1.135-1.146, 2012.

KIMURA, F. Product and process modelling as a kernel for virtual manufacturing environment. Annals of the CIRP, p. 147-150, v. 42, 2003.

LIN, Y.; BIAN, Z.; SUN, S.; XU, T. A two-stage simulated annealing algorithm for the manyto-many milk-run routing problem with pipeline inventory cost. Mathematical Problems in Engineering, 2015.

MAZZALI, L.; MILAN, M. A integração empresa cliente - operador logístico: Uma análise na cadeia Automotiva. Revista Gestão \& Produção, v. 13, n. 2, p. 353-366, mai./ago., 2006.

MERDAN, M.; MOSER, T.; VERBA, P.; BIFFL, S. Investigating the robustness of re-scheduling policies with multi-agent system simulation. International Journal Of Advanced Manufacturing Technology, v. 55(1-4), p. 355-367, 2011.

MOURA, D. A.; BOTTER, R. C. Caracterização do sistema de coleta programada de peças, Milk Run. Revista RAE-eletrônico, v. 1, n. 1, jan./jun., 2002.

NEMOTO, T., HAYASHI, K. e HASHIMOTO, M. "Milk-run logistics by Japanese automobile manufacturers in Thailand." Procedia-Social and Behavioral Sciences 2.3, 5980-5989, 2010 .

NETTO, A. V. et al. Realidade virtual e suas Aplicações na área de Manufatura, treinamento, Simulação e desenvolvimento de Produto. Gestão e Produção, v. 5, n. 2, p. 104-116, 1998.

Nipponexpress. Portal Nippon Express. Disponível em: <http://www.nipponexpress.com/ about/csr/environment/ cooperation.html> Acesso em 9 de junho de 2104.

OLIVEIRA, C. S. Aplicação de técnicas de simulação em projetos de manufatura enxuta. Estudos Tecnológicos, v. 4, n. 3, p. 204-217, 2008.

PÁDUA, S. I. D. Estudo sobre a aplicação do método de avaliação do Modelo de Processos de Negócio do EKD. Produção, v. 22(1), p. 155-172, 2012. 
PIRES, S. R. I. Gestão da Cadeia de Suprimentos (Supply Chain Management). São Paulo: Atlas, 2004.

RATHINASAMY, S.; RAJU, R. Sequencing and scheduling of non uniform flow pattern in parallel hybrid flow shop. International Journal Of Advanced Manufacturing Technology, v. 49(1-4), p. 213-225, 2010.

RODRIGUES, E. F.; ROCHA, A.; ALVES, M.; SOUZA JUNIOR, I.; KAWAMOTO JUNIOR, L. T. Comparação de custo de transporte de entrega utilizando sistema milk run versus entregas ponto a ponto em uma empresa de termoplásticos. GEINTEC-Gestão, Inovação e Tecnologias, 2016, 6.4: 3461-3471, 2016.

ROHM, D. G.; SILVA, E. C. C.; HERMOSILLA, J. L. G.; \& PIRATELLI, C. L. A utilização do Milk Run em um sistema de abastecimento: um estudo de caso. XXX Encontro Nacional de Engenharia de Produção. São Carlos/SP, 2010.

SADJADI, S. J.; JAFARI, M.; AMINI, T. A new mathematical modeling and a genetic algorithm search for Milk run problem (an auto industry supply chain case study). International Journal Of Advanced Manufacturing Technology, v. 44(1-2), p. 194-200, 2009.

TAO, Y.; ZHAO, L.; \& ZHU, D. (2016). Research on Automobile Parts Milk-Run Routing with Unload Time Window.

WOMACK, J. P.; JONES, D. T.; ROOS, D. The machine that changed the world. Simon and Schuster, 2008.

ZHANG, X. F.; ZOU, L. N.; HU, Z. The Study in Supply Chain of Auto Parts Based on MilkRun. Open Journal of Business and Management, 4, 778-783, 2016.

\section{Dados dos Autores}

\section{Joice Ariane Marin}

Mestra em Engenharia de Produção pela Universidade Metodista de Piracicaba. Coordenadora e professora dos cursos de Engenharia de Controle e Automação e Engenharia Elétrica da Faculdade Anhanguera de Sumaré. Sumaré/SP - Brasil. joice.marin@anhanguera.com

\section{André Luís Helleno}

Doutor em Engenharia de Produção pela Universidade Metodista de Piracicaba. Coordenador e Orientador do Programa de Pós Graduação em Engenharia de Produção da Universidade Metodista de Piracicaba. Professor da Escola de Engenharia da Universidade Presbiteriana Mackenzie na área de Planejamento de Processo, Projeto de Fábrica e Planejamento e Controle da Produção. Santa Bárbara d'Oeste/SP - Brasil. alhelleno@unimep.br 


\section{Alexandre Tadeu Simon}

Doutor em Engenharia de Produção pela Universidade Metodista de Piracicaba. Professor do Programa de Pós-Graduação em Engenharia de Produção da Universidade Metodista de Piracicaba. Consultor de empresas com atuação em projetos de implantação de máquinas-ferramenta CNC e automação. Santa Bárbara d’Oeste/SP - Brasil. atsimon@unimep.br

Submetido em: 6-12-2016

Aceito em: 14-3-2017 